\title{
Nietzsche, o perfeccionismo e a democracia: tensões entre Rawls, Cavell e os agonistas
}

\author{
João Kamradt**
}

Resumo: No centro de seu pensamento político, Nietzsche incentiva à busca pela perfeição dos indivíduos. É a disputa pelo significado do perfeccionismo do pensamento de Nietzsche por diferentes correntes o objetivo deste artigo. Rawls faz uma leitura de um perfeccionismo nietzschiano que é elitista, antiigualitário e ligado a regimes aristocráticos. Essa foi uma leitura predominante do pensador. Mas, nos últimos 25 anos, surgiram outras interpretações para a busca pela perfeição nietzschiana. Uma defende um perfeccionismo moral no pensamento do autor, que seria igualitário e compatível com o ambiente democrático. Outra, mais recente, argumenta em prol de um perfeccionismo agonístico, visando a perpétua luta para superação de si mesmo como fundamental para o ambiente democrático.

Palavras-chave: perfeccionismo - Nietzsche - igualdade democracia - aristocratismo.

* Doutorando do Programa de Pós-Graduação em Sociologia Política da Universidade Federal de Santa Catarina. Correio eletrônico: joaokamradt@gmail.com 
Kamradt, J.

\section{As diferentes interpretações do perfeccionismo nietzschiano}

É cada vez mais extenso o volume de interpretações e indagações acerca da recepção do perfeccionismo em Nietzsche. Interpretações que enxergam um potencial inexplorado do perfeccionismo nietzschiano como um importante ingrediente para a revitalização da democracia liberal. São os significados desse perfeccionismo nietzschiano que estão em disputa. Foi John Rawls, em A Teoria da Justiça (2002), o responsável por iniciar esse debate, ao alegar existir um perfeccionismo político em Nietzsche, que é completamente incompatível com a democracia. A interpretação desencadeou um intenso debate, sendo que outras duas correntes disputam qual seria a serventia que essa interpretação da busca pela perfeição no pensamento nietzschiano teria. A resposta de Stanley Cavell a Rawls, em sua obra Conditions Handsome and Unhadsome: The Constitution of Emersonian Perfectionism, de 1988 - apoiada em outros teóricos, como James Conant (2001) - se destaca. Cavell buscou criar uma ponte entre o perfeccionismo de Nietzsche com um tipo específico de ideal da democracia liberal inspirado no que ele chama de perfeccionismo emersoniano. Neste contexto, Nietzsche passou a ser vinculado a um individualismo liberal que, além de não possuir nada de elitista, ainda seria igualitário e compatível com o liberalismo democrático.

Na esteira dessas duas visões, uma terceira vertente vem se estabelecendo recentemente: é a corrente do perfeccionismo agonístico, que aponta para a possibilidade da utilização dessa perfeição para renovar o ambiente democrático e liberal ${ }^{1}$. Essa corrente surgiu apontando um perfeccionismo agonístico que seria compatível com um tipo de democracia liberal, sendo um tipo que não defenda a igualdade niveladora de seus indivíduos. Para esses

1 Cf. HATAB, 1995; OWEN, 1995; 2002; LEMM, 2009.

208 Cad. Nietzsche, Guarulhos/Porto Seguro, v.38, n.3, p. 207-235, setembro/dezembro, 2017. 
Nietzsche, o perfeccionismo e a democracia: ...

comentadores, Nietzsche prega a perpétua busca por melhora dos indivíduos, por um agon contínuo em que os sujeitos e as instituições sempre estarão se colocando à prova, e por estarem continuamente em disputas, nunca haverá vencedores definitivos. Ou seja, nenhum indivíduo conseguirá alcançará um estágio de perfeição, um telos. Isso porque sempre estarão lutando por uma perpétua melhora. E ao disputarem esses confrontos agonísticos, invariavelmente, fariam disso uma melhora coletiva propagada por toda a sociedade, já que a luta agonística sempre prevê um Outro que coloque o indivíduo continuamente à prova.

O debate em torno do tipo de perfeccionismo nietzschiano é relevante e importante para a teoria política contemporânea. Em suas críticas, Nietzsche entende que a igualdade liberal pode provocar a neutralização dos indivíduos. Assim, o pensador quer fornecer a todos uma medida favorável para a elevação do homem. Será o rastreamento das diferentes interpretações do perfeccionismo nietzschiano o objetivo deste artigo.

\section{A crítica rawlsiana ao perfeccionismo de Nietzsche}

Em A Teoria da Justiça, Rawls faz uma leitura elitista e aristocrática do perfeccionismo de Nietzsche. Sua conclusão é baseada a partir de uma única passagem de um dos inúmeros livros publicados pelo autor, retirada do início da sexta seção do ensaio Schopenhauer como Educador. A análise de Rawls foi a responsável por uma polêmica ao redor das interpretações que situam Nietzsche no centro da problemática contemporânea do perfeccionismo.

Em Schopenhauer como Educador, Nietzsche faz inúmeras referências a uma busca por indivíduos superiores, pela autossuperação do indivíduo e pela necessidade de que o Estado trabalhe visando a maximização das possibilidades humanas. Independentemente dessas passagens, os pensamentos de Nietzsche estão voltados mais 
Kamradt, J.

diretamente ao problema da cultura do que a questão de como formar uma constituição forte, combatendo o que ele classifica como o espírito decadente que prevalece em sua época, principalmente nas instituições democráticas e de ensino.

Para Rawls, existem duas variáveis responsáveis por dar forma a uma concepção perfeccionista. A primeira consiste no que ele afirma ser como um princípio único de uma teoria teleológica que "dirige a sociedade a organizar as instituições e a definir os deveres e obrigações dos indivíduos de modo a maximizar a perfeição das realizações humanas na arte, na ciência e na cultura" (Rawls, 2002, p. 359). A outra menção ao perfeccionismo é definida pelo estadunidense como uma forma de perfeccionismo mais moderada. Ele defende que este segundo modelo apresenta argumentos mais consistentes, porque se aceitaria o princípio da perfeição somente como "um entre vários padrões de uma teoria intuicionista" (Rawls, 2002, p. 359). Mesmo assim, ele rejeita fortemente esta possibilidade devido à prioridade que o justo tem sobre o bem em sua teoria. Esta última concepção de perfeccionismo é apresentada por Rawls tendo Aristóteles como seu representante principal e maior exemplo. Em vista do estudo que desenvolvo, deixarei de lado a visão de Aristóteles e focarei na primeira articulação do perfeccionismo. Esta articulação, para ele, é uma expressão do que seria o perfeccionismo político e teria como figura exemplar Nietzsche.

Antes de chegar à citação de Nietzsche feita por Rawls, é necessário entender que ele a faz em um momento no qual busca afirmar e ilustrar sua condenação aos princípios perfeccionistas. Princípios que Rawls entende como antidemocráticos e elitistas.

Obviamente, o princípio é tanto mais exigente quanto mais elevado for o ideal estabelecido. $O$ peso absoluto que Nietzsche algumas vezes confere à vida dos grandes homens tais como Sócrates e Goethe é incomum. Em certas passagens, ele diz que a humanidade deve se esforçar continuamente para produzir grandes homens. Devemos dar valor às nossas vidas trabalhando para o bem dos indivíduos mais distintos (Rawls, 2002, p. 359).

$210 \mid$ Cad. Nietzsche, Guarulhos/Porto Seguro, v.38, n.3, p. 207-235, setembro/dezembro, 2017. 
Embora use Nietzsche como exemplo, a citação feita pelo teórico da justiça do filósofo alemão se constitui de uma nota de rodapé. Nesta nota, ele critica a fala de Nietzsche de que a humanidade deve trabalhar continuamente na produção de grandes homens e de que o maior valor das vidas deve estar em voltar-se para o favorecimento destes indivíduos superiores. Isso serve para demonstrar sua rejeição à doutrina perfeccionista. A passagem que Rawls utiliza de Nietzsche é a seguinte:

A humanidade deve trabalhar continuamente para produzir grandes seres humanos singulares - nisso e nada mais consiste sua tarefa [...], pois a questão é a seguinte: como pode a tua vida, a vida individual, reter o valor mais elevado, a significação mais profunda? [...] Apenas vivendo para o bem dos mais raros e valorosos espécimes (SE/Co. Ext. III, KSA 1.384).

Para Rawls, essa passagem entra em conflito direto com o primeiro princípio de justiça da sua teoria da justiça. Esse princípio tem como foco à liberdade e a igualdade entre os indivíduos, buscando incluir todos os indivíduos dentro da mesma estrutura básica em uma situação de igualdade. Assim, garantiria a eles suas liberdades básicas, como a liberdade de expressão, a liberdade política, a liberdade de consciência, de propriedade, de coerção psicológica e de agressão física. Além do confronto com um dos argumentos fundamentais de sua teoria, Rawls também apresenta uma preocupação de fundo institucional e político. Isso porque, na sua interpretação, Nietzsche, com sua assertiva, estaria sugerindo que a sociedade fosse ordenada em uma estrutura na qual todas as instituições governamentais tivessem como finalidade a busca e a tentativa de favorecimento de determinados indivíduos, da criação e do consequente surgimento desses indivíduos superiores, destes indivíduos de exceção.

$\mathrm{Na}$ ótica de Rawls, mesmo que somente um grau mínimo de recursos sociais fossem destinados à promoção de um objetivo que 
Kamradt, J.

buscasse a perfeição de seus indivíduos, estas reivindicações ainda se chocariam com as necessidades mais básicas exigidas pelos seres que compõem a sociedade. Além de também contrariar a distribuição das liberdades e de outros bens primários. Isso também iria na contramão da distribuição de outros bens primários e da liberdade. Mais do que isso, através dos princípios de justiça seria possível "definir um ideal de pessoa sem invocar um padrão anterior de excelência humana" (Rawls, 2002, p. 361). Para Rawls, aceitar um princípio como o que ele alega ter sido proposto por Nietzsche levaria a uma redução ou até mesmo à perda total da liberdade dos indivíduos. Isso porque, uma vez que o princípio da perfeição fornecesse uma base insegura para as liberdades iguais, colocaria em xeque sua proposta de que na posição original os indivíduos firmassem o compromisso de que todos devem ter a maior liberdade igual possível. Como ele afirma na seguinte passagem:

Se fossem avaliadas pela doutrina do perfeccionismo, as atividades de muitos grupos não revelariam um grau elevado de excelência. [...] $\mathrm{O}$ nível absoluto de realização, ainda que pudesse ser definido, é irrelevante. Em qualquer caso, no entanto, devemos, como cidadãos, rejeitar o padrão de perfeição enquanto princípio político e, no que respeita à justiça, evitar qualquer avaliação do valor relativo do modo de vida dos outros. [...] as partes na posição original não adotam o princípio da perfeição (Rawls, 2002, p. 338).

Isso porque, uma vez em que o princípio da perfeição fornecesse uma base instável para liberdades iguais, colocaria em xeque sua proposta de que na posição original os seres viessem a firmar compromissos em que todos deveriam ter a maior liberdade igual possível. 
Nietzsche, o perfeccionismo e a democracia: ...

\section{A defesa de um perfeccionismo moral igualitário em Nietzsche}

A leitura feita por John Rawls sobre o perfeccionismo de Nietzsche foi predominante por quase vinte anos nos Estados Unidos. Foi somente quando Stanley Cavell $(1990 ; 1993)$ se opôs à visão de um perfeccionismo elitista, aristocrático e antidemocrático do filósofo de Röcken que as possibilidades do aproveitamento do perfeccionismo nietzschiano foram retomadas. Cavell saiu em defesa do perfeccionismo de Nietzsche argumentando que este era igualitário e compatível com a democracia liberal. O objetivo de Cavell era defender o pensamento do ensaísta democrata Emerson - Cavell enxergava similaridades entre Nietzsche e Emerson. Cavell centra sua defesa no perfeccionismo moral emersoniano. Embora o perfeccionismo político que Rawls atribui a Nietzsche esteja distante do perfeccionismo moral que Cavell defende, este entende que, ao atacar Nietzsche, Rawls indiretamente rejeitou o perfeccionismo emersoniano. Cavell enxerga em Nietzsche um perfeccionismo moral em que impera a busca pela perfeição dos indivíduos.

O desacordo que eu tenho com Uma Teoria da Justiça é que o que implicitamente chamo de "perfeccionismo emersoniano" está retornando como intrinsicamente antidemocrático ou elitista, enquanto que de minha parte acho que a versão emersoniana do perfeccionismo é essencial para uma crítica interna da democracia. [...] Em A Teoria da Justiça, a seção 50 , que é dedicada ao perfeccionismo, Rawls lê em Nietzsche o que ele chama da versão forte do perfeccionismo. Rawls, em seguida, rejeita essa concepção para uso na arena da teoria democrática da justiça, argumentando, ao que me parece ser [...] uma leitura errada ou muito monolítica de um conjunto de frases de Nietzsche. $\mathrm{O}$ que mais me fascina nesta rejeição de Nietzsche é que a passagem em questão é virtualmente uma transcrição de passagens de Emerson e, portanto, em algum ponto do livro de Rawls se produz a rejeição do pensamento de Emerson (Cavell, 1993, pp. 49-50). 
Kamradt, J.

Segundo Cavell, Rawls entende a filosofia de Nietzsche como uma exaltação para a criação de uma classe de grandes homens, em que o resto da sociedade terá que se contentar em viver por causa deles e para sustentar a concepção de bem daqueles poucos indivíduos. Cavell aponta quatro equívocos de interpretação de Rawls. O primeiro é de que não há nada no texto de Nietzsche, ele se refere a Schopenhauer como educador, que vise a maximização da distribuição de qualquer coisa que pertença à grande cultura na atual forma institucionalizada. Ele entende a cultura como já sendo distribuída universalmente. "O que significa dizer que ela faz parte de uma concepção de como é ser uma pessoa moral" (Cavell, 1993, p. 73).

O segundo argumento contestado por Cavell é de que o perfeccionismo nietzschiano se constitui como uma doutrina teleológica. Cavell responde que se o desenvolvimento pode ser descrito como uma maximização, ainda assim permanece o fato de que cada indivíduo precisará desenvolver a própria cultura e não a dos outros. Em suma, a visão de Nietzsche, segundo Cavell, é de que o conflito pela cultura não se constitui apenas como uma luta pela própria cultura e pelo autodesenvolvimento do indivíduo, mas também como uma disputa pela transformação da sociedade em que possa vir a ser necessário que todos os indivíduos tenham que se sacrificar.

O terceiro argumento de Cavell é de que tanto Nietzsche quanto Emerson são contrários às instituições. De acordo com Cavell, Nietzsche e Emerson possuíam uma atitude de desprezo pela cultura oficial, o que por si só já seria um fato a favor de uma noção democrática. Em Schopenhauer como educador, Nietzsche faz uma dura crítica às instituições de ensino da Alemanha, defendendo que no futuro seja realizada uma reforma nessas organizações para que elas possam servir para o incentivo dos indivíduos de exceção. $\mathrm{O}$ quarto e último argumento apontado por Cavell é de que Nietzsche 
Nietzsche, o perfeccionismo e a democracia: ...

não estaria defendendo que a humanidade trabalhe para alguns poucos indivíduos de exceção. A conclusão de Cavell é de que Nietzsche dedicou e viveu sua vida para si mesmo e que, em Schopenhauer como educador, ele sugere para todos fazerem o mesmo. É por isso que o perfeccionismo de Nietzsche possuiria características liberais indispensáveis para uma crítica interna ao processo democrático.

Essa ênfase do perfeccionismo, como eu já disse, pode ser tomada para servir num esforço para escapar da mediocridade ou do nivelamento, digo vulgaridade, da igualdade da existência, por si mesmo e talvez, para um círculo restrito de outros pensamentos similares (Cavell, 1990, p. 56).

Segundo Cavell, Nietzsche entende que a vida na cultura necessita ser compreendida como uma vida "vivida para o bem daquele que a vive" (Cavell, 1990, p. 51), sendo assim individual. Essa vida não deve ser entendida dentro de um sistema político e social que venha a privilegiar uma minoria a partir dos sacrifícios realizados por uma maioria. Para Cavell, o perfeccionismo de Nietzsche é compatível com o liberalismo e necessário para o seu contínuo desenvolvimento. Isso porque os indivíduos precisam cultivar a si mesmos e necessitam se desenvolver dentro de uma sensibilidade que seja não-gregária.

Cavell argumenta que o conceito de cultura colocado na Terceira Extemporânea de Nietzsche deve ser entendido como antiinstitucional. Como a capacidade moral de cada ser para o autoaperfeiçoamento é distribuída de uma forma universal, a vida desde esse momento inicial irá assumir uma qualidade igualitária, tornando possível pensar o perfeccionismo de forma conjunta a políticas democráticas, já que "o desprezo particular pela cultura oficial tomada em Emerson e Nietzsche é a própria expressão da democracia e do compromisso com ela" (Cavell, 1990, p. 50). Para que exista uma verdadeira democracia, a sociedade deve ser composta por seres que possuam vozes distintas. Assim, o perfeccionismo de Emerson 
Kamradt, J.

e Nietzsche funciona como uma medida de crítica interna a essa democracia, se destacando pelo significado padrão do perfeccionismo moral, ao não ser uma teoria teleológica. O argumento de Cavell é de que se o autoconhecimento seria a fórmula para a cultura e para a insatisfação consigo mesmo, então não haveria nenhum sentido em imaginar o modelo de Nietzsche como algo externo.

Outro problema enxergado na leitura de Rawls de Schopenhauer como educador é abordado por James Conant. Segundo ele, a noção de exemplar de Nietzsche envolve três aspectos: 1) um exemplar só pode ser comparado com outro membro do seu próprio gênero; 2) um exemplar possuirá características que outros membros também exibirão em diferentes graus; e 3) um exemplar só é distinguido de outros indivíduos semelhantes a partir do grau de virtude ou perfeição que apresenta a mais do que os outros. Além disso, Conant enfatiza que isso não é uma postura contrária à democracia:

Muitos teóricos da democracia têm percebido dentro do "movimento democrático" uma tendência à supressão da capacidade da democracia de fazer críticas internas a si mesma - uma pressão ao colapso à (como chamou Tocqueville) "tirania da maioria". John Adams, Matthew Arnold, William James, Thomas Jefferson, Alexander Hamilton, John Stuart Mill, Alexis de Tocqueville (para não mencionar Emerson e Thoreau), todos temem aquele rebaixamento da democracia que tanto Mill quanto Emerson se referem como "o despotismo da conformidade". Há uma tensão perfeccionista dentro da tradição do pensamento democrático que toma como uma questão de preocupação urgente que as tendências antiperfectionistas latentes dentro do movimento democrático sejam impedidas de corroer os recursos da democracia para a realização de críticas internas - aí que a pressão de tal crítica é considerada como sendo essencial para a capacidade da democracia de permanecer fiel às suas próprias aspirações (Conant, 2001, p. 227).

Além disso, para Cavell e Conant, a compreensão de Rawls da palavra "especimen" fez o filósofo do direito compreender o termo como uma referência aos indivíduos de uma classe minoritária. Essa classe seria a responsável por exigir um sacrifício da maioria em 
prol de seu benefício, necessitando que todos os esforços fossem direcionados em uma direção que tornasse possível a eles maximizar o valor de suas próprias vidas. Na interpretação de Cavell, o detalhe é que esse exemplar, na compreensão da palavra reproduzida no texto de Nietzsche, não iria se refletir na figura de um outro, nem na relação do sujeito com os demais indivíduos. Assim, Cavell entende o exemplar se espelhando com o próprio eu superior.

Retornando a interpretação de Conant (2001), este argumenta que Nietzsche preserva quatro características teorizadas por Kant. Estas seriam de que o gênio representa uma espécie de excelência que faz exigência aos outros; demanda essa não formulada em termos de regra explícita e também não alcançável através de um governo de regras; demanda que necessita um parecer favorável do restante dos indivíduos; e na qual a concordância expressa um esforço para tratar esse "gênio" ou indivíduo de exceção como um exemplo a ser seguido ou emulado. Vaccari concorda com a visão de Conant, argumentando que a teoria perfeccionista de Nietzsche pode ser encaixada dentro do registro de vida moral defendido por Cavell. Segundo Vaccari (2010), a linha perfeccionista atravessa todo o arco do pensamento de Nietzsche e constitui a base de várias linhas da crítica do autor a moralidade:

O cultivo de nosso gênio é uma condição para estarmos aptos a desenvolver a capacidade para reconhecer e responder às necessidades reais das outras pessoas. No referencial perfeccionista de Nietzsche, a melhor maneira de ajudar os outros não é escolher por eles, mas cultivar e construir em si mesmo um exemplo de como uma vida individual pode receber o valor máximo (Vaccari, 2010, p.187). 
Kamradt, J.

\section{Primeiro político, depois moral: a interpretação de Conway}

Conway alega que o perfeccionismo de Nietzsche é um conceito presente e desenvolvido durante toda sua obra. A principal diferença entre seu entendimento e o de Cavell é que Conway acredita que Nietzsche defendeu o perfeccionismo político, como argumenta Rawls, e depois mudou sua interpretação e passou a defender um perfeccionismo moral. Se há entendimentos equivocados sobre o real significado do perfeccionismo na obra nietzschiana, o próprio filósofo da moral pode ser responsabilizado por parte desse mal-entendido.

O núcleo ético do perfeccionismo de Nietzsche muitas vezes é eclipsado por seu ataque mordaz à tradição moral ocidental. Mas sua crítica da moralidade não é inóspita para todas as formas de moralidade e ela de fato abre um espaço para a "moralidade da reprodução" que motiva o seu perfeccionismo. Ele realmente tem a intenção de que seu perfeccionismo abrigue um pluralismo moral, informado por uma ordem de classificação, a qual produz uma organização hierárquica de comunidades éticas (Conway, 1997, p. 27).

Mesmo assim, no entendimento de Conway, ao rejeitar o perfeccionismo nietzschiano por acreditar no seu anti-igualitárismo, Rawls rejeita um programa de educação moral adequado para a formação de cidadãos em uma sociedade democrática. Independente disso, Conway concorda com a posição de Rawls de que o perfeccionismo nietzschiano seria melhor atendido por regimes aristocráticos. No seu entendimento, o conjunto da obra de Nietzsche dá argumentos tanto para a defesa de um tipo de perfeccionismo anti-igualitário quanto para um perfeccionismo do tipo igualitário.

Conway entende a crítica de um perfeccionismo político feita por Rawls ao pensamento nietzschiano como útil e necessária para abrir o caminho para o entendimento de que há um perfeccionismo moral, como argumentado através da interpretação de Cavell. Conway

218 Cad. Nietzsche, Guarulhos/Porto Seguro, v.38, n.3, p. 207-235, setembro/dezembro, 2017. 
Nietzsche, o perfeccionismo e a democracia: ...

conceitua que o perfeccionismo político deve ser compreendido como algo que prevê uma estratificação rígida e uma organização hierárquica da sociedade e dos seus recursos, com o objetivo de produzir aqueles seres humanos exemplares cujas façanhas irão garantir o futuro da humanidade. Por sua vez, o perfeccionismo moral deve ser entendido em termos de uma convicção na qual a principal obrigação ética seria atender a maior perfeição de si mesmo (Conway, 1997, p. 51). Segundo $o$ autor, o perfeccionismo moral não deve necessariamente anteceder um perfeccionismo político na sociedade. Para Conway, Nietzsche possui um pensamento abertamente antiliberal e anti-igualitário. Logo, a forma de conseguir conciliar seu pensamento com os ideais orientados pelo liberalismo seria restringir seu perfeccionismo moral à esfera privada.

Segundo Conway, o perfeccionismo nietzschiano pode ser separado do aristocratismo como um regime político, funcionando de forma independente deste. Segundo ele, é somente a partir de Assim Falou Zaratustra, que o filósofo passa a defender um perfeccionismo moral.

Enquanto nada lhe agradaria mais do que contribuir para o estabelecimento de um regime aristocrático, ele também percebe que a vitalidade empobrecida da modernidade é simplesmente incompatível com o perfeccionismo político que idealiza. Sua mudança subsequente de ênfase para o perfeccionismo moral não apenas é coerente com sua crítica da modernidade, como também transmite a prioridade que ele sempre atribuiu à ética em relação à política (Conway, 1997, p. 51). ${ }^{2}$

A autossuperação dos indivíduos de exceção para Nietzsche seria baseada em um princípio de assimilação ou de incorporação

2 "Mas os autênticos filósofos são comandantes e legisladores: eles dizem 'assim deve ser!', eles determinam o para onde? E para quê? do ser humano, e nisso têm a seu dispor o trabalho prévio de todos os trabalhadores filosóficos, de todos os subjugadores do passado estendem a mão criadora para o futuro, e tudo que é e foi torna-se para eles um meio, um instrumento, um martelo. Seu 'conhecer' é criar, seu criar é legislar, sua vontade de verdade é - vontade de poder. Existem hoje tais filósofos? Já existiram tais filósofos? Não têm que existir tais filósofos?” (JGB/BM 211, KSA 5.145).

Cad. Nietzsche, Guarulhos/Porto Seguro, v.38, n.3, p. 207-235, setembro/dezembro, 2017. 
Kamradt, J.

pela parte de outros sujeitos (Conway, 1997, p. 51). Por isso, Conway acredita que o perfeccionismo de Nietzsche será melhor entendido como uma tentativa de aderir à perspectiva do filósofo legislador.

Segundo ele, o perfeccionismo moral, identificado por Conway no pensamento de Nietzsche, só poderia ser realizado através do agon.

\section{Nem moral, nem político: um perfeccionismo nietzschiano agonístico}

Outros comentadores passaram a reivindicar um perfeccionismo não teleológico de base agonística no pensamento de Nietzsche. Entre seus defensores estão David Owen, Lawrence J. Hatab, Herman Siemens e Vanessa Lemm. Lemm ${ }^{3}$ se posiciona contrariamente às alternativas e teses apresentadas tanto por Cavell quanto por Rawls. Embora sua premissa seja oferecer uma alternativa à leitura perfeccionista, ela continua demonstrando uma inclinação positiva para o perfeccionismo de Nietzsche. Essa interpretação decorre da interpretação que faço do uso dado por Lemm ao agonismo. Ela não afirma que Nietzsche é elitista, mas também não defende um Nietzsche liberal. A leitura de Lemm procura fornecer uma

[...] leitura não perfeccionista da filosofia da cultura de Nietzsche, a qual permanece fiel aos propósitos da discordância de Cavell com Rawls por não sucumbir ao preconceito contra os valores de um "aristocrata radical" e apreciar sua contribuição potencialmente frutífera para a política democrática (Lemm, 2007, p. 6).

Ao buscar desvencilhar Nietzsche do perfeccionismo, Lemm acaba obtendo o resultado oposto. Sua interpretação se aproxima de uma concepção política da cultura concebida como uma questão pública que pressupõe uma pluralidade de agentes envolvidos em

3 Em artigo anterior, Nietzsche y la libertad individual: Rawls, Cavell y el debate sobre el valor del perfeccionismo para la democracia (2007), ela já havia plantado as bases para sua futura análise.

$220 \mid$ Cad. Nietzsche, Guarulhos/Porto Seguro, v.38, n.3, p. 207-235, setembro/dezembro, 2017. 
Nietzsche, o perfeccionismo e a democracia: ...

disputas agonísticas, visto que há determinados contextos individuais envolvendo elementos de disputas sem vencedores e sem fim, ou seja, em uma busca constante por se automelhorar continuamente.

Nesse sentido, o que confere o maior valor e o significado mais profundo à vida não é o aumento da perfeição moral individual, mas a crescente pluralização e a diversificação da vida. A pluralização da vida alcançada pelos exemplares mais elevados tem tanta importância para Nietzsche não só porque reflete uma relação livre com o outro, mas também porque tem um efeito libertador sobre o outro. A liberdade que me vincula ao exemplar mais elevado, e não ao exemplar moralmente superior, é a que aumenta o valor e aprofunda o sentido da vida do indivíduo (Lemm, 2009, pp. 98-99).

Para ela, a cultura é uma "[...] luta pública que gera não apenas a liberdade individual, mas também a liberdade da sociedade" (Lemm, 2009, p. 101). Segundo Lemm, Nietzsche entende o valor dos indivíduos como uma questão em aberto. Isso porque essa questão é reconfigurada constantemente por ocasião do confronto do indivíduo com o desafio da responsabilidade. Lemm propõe que a política da cultura de Nietzsche deve ser lida como aristocrática e democrática. Nietzsche defende o valor de que todos os indivíduos sejam desiguais e se distingam uns dos outros. Para Nietzsche, o conceito de cultura irá pressupor uma natureza anti-institucional que não pode ser maximizada por meio da organização social e política (Lemm, 2007, p. 11).

Segundo a interpretação de Lemm, a noção de responsabilidade de Nietzsche é plural e incompatível com a ideia de uma perfeição moral que esteja circunscrita na relação do self consigo mesmo (Lemm, 2009, p. 94). Lemm explica que o conceito de responsabilidade é um valor aristocrático, alegando que cada indivíduo assume uma forma única e irredutível. Segundo ela, Nietzsche estaria interessado em uma responsabilidade que não fosse de natureza moral ou política. Mas ao buscar a contínua melhora, isso ironicamente seria perfeccionista. Segundo Lemm, 
Kamradt, J.

[...] a liberdade individual, de acordo com Nietzsche, se dá por meio da prática de uma política agonística de responsabilidade e, portanto, excede a realização da justiça por meio do autoaperfeiçoamento moral individual (Cavell) e a realização mediante a constituição de uma "estrutura básica" justa da sociedade (Rawls) (Lemm, 2009, p. 101).

Lemm também não concorda com a interpretação feita por Cavell, que apresenta Nietzsche como um perfeccionista moral sem levar em conta que a cultura tem um significado político agonístico, como uma luta pública que irá se estabelecer entre a sociedade e o indivíduo. Na interpretação de Lemm, o termo "luta pela cultura" é outro nome possível dado por Nietzsche para esta abertura do indivíduo à alteridade. $\mathrm{O}$ questionamento de Nietzsche do valor e do significado da vida individual é historicamente situado. Lemm, aliás, argumenta também que o desenvolvimento dos gênios, desses indivíduos de exceção tidos como o objetivo da cultura, avançaria continuamente na luta agonística contra os adversários da cultura.

O compromisso de Nietzsche se encontra com a humanidade e não com a sociedade. O filósofo alemão não tem em mente uma busca pelo bem-estar social e o bem-estar individual não é sua maior preocupação. Ele entende que o bem-estar representa um sintoma de decadência, pois ao colocar a dor e o prazer em primeiro lugar o indivíduo já é um decadente. Isso porque um indivíduo com vontade de ascensão não pensaria de tal forma, já que teria uma tarefa a cumprir. Além de sintoma de decadência, a moral hedonista, ao colocar o bem-estar em primeiro lugar, impede o surgimento de indivíduos criativos e de exceção, pois a criação surge de um processo de sofrimento e esse sofrimento também pode estimular a criação. $\mathrm{O}$ problema com a moderna moral hedonista é que ela tenderia a criar uma sociedade de últimos homens.

Assim, em Schopenhauer como educador, o que Nietzsche mostra é que, embora exista uma preocupação com o aspecto individual e particular com aqueles indivíduos de exceção, esse incômodo reflete 
Nietzsche, o perfeccionismo e a democracia: ...

um pedido, um apelo que acontece em relação ao outro e que está a favor da humanidade. É esse o raciocínio que segue esse trecho da seção seis de Schopenhauer como educador:

Quão resolutamente oporíamos a mais forte resistência aos prejuízos adquiridos sobre a finalidade da sociedade! Em verdade, nada seria mais fácil do que compreender que o objetivo de sua evolução se encontra ali onde uma espécie tenha alcançado seu limite e começa agora sua transmutação a outra espécie superior, e não certamente ao bem-estar da massa e seus exemplares ou aqueles exemplares que de um ponto de vista estritamente temporal são os últimos. Este propósito parece ter se cumprido em algumas existências dispersas e casuais que, aqui e ali, cobram vida em circunstâncias favoráveis. E ainda mais difícil resultaria a compreensão da exigência de que a humanidade busque e produza, precisamente pelo fato de poder ascender à consciência de seu fim, as condições favoráveis e necessárias para o surgimento daqueles grandes homens chamados a redimi-la e liberá-la (SE/Co. Ext. III, KSA 1.384).

O perfeccionismo presente no pensamento de Nietzsche, tanto da ótica de Cavell quanto na de Lemm (mesmo que esta tenha ignorado que suas interpretações de Nietzsche levam ao agonismo perfeccionista), poderia ir ao encontro de políticas democráticas. Não há problema em enxergar a natureza como um organismo em perpétua superação. A superação é exatamente o objetivo do perfeccionismo de Nietzsche. Tratando da segunda consagração da cultura, Nietzsche reflete sobre esse momento através da relação agonística existente entre o tempo, as leis, os costumes e as crenças de uma época. Isso já pressupõe um contato com o outro, já que não se trata de um embate que visa exclusivamente ao próprio proveito. Da mesma forma, instituições, crenças, costumes ou leis não terão sentido se forem concebidas em uma esfera particular. Ir em direção da cultura favorece o surgimento dos indivíduos de exceção e isso para Nietzsche é um avançar da natureza em direção a sua evolução e a contínua busca pela perfeição. 
Kamradt, J.

É possível afirmar que, havendo um perfeccionismo em Nietzsche, este se encontra no modo como o filósofo percebe a natureza. Levando em conta esta tese, só faz sentido afirmar que a principal preocupação de Nietzsche está nos limites da humanidade, pois a evolução que passariam os indivíduos de exceção respingaria em todos os humanos. Por isso, Lemm defende que Nietzsche usa o termo gênio para se referir a algo além do eu individual, que vem com o self e com a responsabilidade (Lemm, 2009, p. 96). Esse eu exterior teria um papel fundamental na imagem do filósofo como educador, que é como Lemm imagina a perspectiva de Nietzsche sobre Schopenhauer. Esse tipo de perfeccionismo teria como objetivo "superar uma forma de vida social e política determinada e gerar variações e alterações para enobrecer formas mais livres da vida por vir" (Lemm, 2009, p. 101).

Uma terceira via apontou que uma disputa na cultura resultaria no desenvolvimento dos indivíduos e da sociedade, resgatando elementos agonísticos na obra de Nietzsche. Ao formular uma concepção de um perfeccionismo agonístico, Owen, de um lado, demonstra a preocupação de Nietzsche com o "movimento democrático de nossos tempos" (Owen, 2002, p. 113), sem que isso se impusesse como uma crítica efetiva ao sistema democrático. Por sua vez, Hatab interpreta que Nietzsche tinha traços de anti-igualitarismo, mas sua posição seria contra um igualitarismo que não pode ser colocado como a condição sine qua non da política democrática, pois sua crítica era voltada ao fato de que a democracia apresentava uma tendência para exprimir uma vontade de igualdade, responsável por nivelar os indivíduos por baixo e promover a conformidade. Hatab defende ser justo tratar as pessoas de forma desigual em determinados contextos. Da mesma forma, defende a possibilidade de ser democrático dando oportunidade para que todos possam se provar e possam buscar a excelência. Tanto Hatab como Owen defendem que esse perfeccionismo consiste em acordar (através da prática 
Nietzsche, o perfeccionismo e a democracia: ...

contínua) uma posição em relação a nós mesmos como seres que nos desafiamos (Owen, 2013, p. 78). Segundo Owen, uma das críticas que Nietzsche destina ao tipo de igualdade associado normalmente à democracia é o fato dela acabar diminuindo as possibilidades de autossuperação do indivíduo. Como Owen aponta, a preocupação de Nietzsche com a igualdade niveladora está em consonância com os pontos de vista de teóricos perfeccionistas da democracia, como Emerson e Mill, antecipando e respondendo preocupações e críticas da democracia do bem-estar. Hatab (1995) é outro a apresentar a defesa contra quem chama a filosofia nietzschiana de antidemocrática a partir da distinção de Nietzsche da moral do mestre (que expressa a vontade ativa para poder) e a moral dos escravos (que exprime a vontade reativa ao poder). Nietzsche desmascara valores tidos como aparentemente ativos da sociedade, como a universalidade, a igualdade, a harmonia, o conforto e a proteção. Elementos motivados por atitudes reativas, como o medo do perigo e da diferença, o ódio do sofrimento, o ressentimento e a vingança contra a excelência e o poder. Hatab defende que a meta prioritária de Nietzsche é a deslegitimação do discurso da igualdade libertária que, como a moral dos escravos, se apresenta como positiva, mas acaba sendo uma negação reativa, responsável por um nivelamento das diferenças, ofendendo constantemente a afirmação de Nietzsche das distinções e exigindo uma demarcação contra o Outro (Hatab, 1995, p.29). Para ele, a democracia é fluída o suficiente para aceitar um certo tipo de elitismo cultural, desde que tenha junto um modo de se proteger da tirania, que nesse caso seria através do seu sistema meritocrático e agonístico, elemento responsável por policiar contra a exclusão e pela manutenção de regras de "fair play". Como Hatab argumenta, Nietzsche quer "desafiar a retórica igualitária, minar o ressentimento e a mediocridade e incentivar a retórica da excelência - ao mesmo tempo, no entanto, que se afirma e se sustenta uma política democrática" (Hatab, 1995, p. 110). 
Kamradt, J.

Owen enfatiza o fato de a defesa de uma postura perfeccionista do pensamento nietzschiano poder ser defendida através do agon. Nietzsche entende que os indivíduos e as instituições necessitam do agon para alcançar uma vida mais produtiva: "sem inveja, ciúme e ambição de disputa, tanto a cidade grega como o homem grego degeneram" (CV/CP, KSA 1.792). O perfeccionismo agonístico funciona como uma contestação perpétua das instituições e dos valores fundamentais de uma comunidade política. Não haveria final e nem vencedor. O agon surge na filosofia nietzschiana no ensaio "A Disputa de Homero", parte do livro Cinco prefácios a cinco livro não escritos. Para Nietzsche, a antiguidade grega era um meio para se alcançar a compreensão sobre nós mesmos, para que pudéssemos nos julgar e superar. Assim, um dos aspectos que teriam despertado a atenção de Nietzsche na cultura grega antiga foi o espírito de competição, seja no campo político, artístico ou atlético. "A luta é cura, salvação; a crueldade do vencedor é o maior júbilo da vida" (CV/CP, KSA 1.785). É por isso que, para Hatab, a filosofia de Nietzsche demonstra que qualquer desenvolvimento da cultura requer desconforto, resistência e superação. $\mathrm{O}$ ideal ascético é precisamente o desejo de escapar da dificuldade de incorporar o Outro em sua área de atuação (Hatab, 1995, p. 48). Hatab acredita que o self é formado dentro e através de relações agonísticas. Assim, um caminho em direção a um Outro acaba se constituindo como um caminho em direção à abertura de si mesmo (Hatab, 1995, p. 49). Hatab argumenta que a prática democrática defende valores semelhantes. Juízos políticos não são predestinados ou ditados; vencedores são peneirados dos perdedores através de uma competição de discursos; eleições democráticas estabelecem as condições de controle temporário e a subordinação da população pode ser alterada por causa da sucessão de competições políticas periódicas. Se lembrarmos que o conceito de poder de Nietzsche não é limitado à força física, podemos ver uma vontade de potência na democracia (Hatab, 1995, p. 63).

226 Cad. Nietzsche, Guarulhos/Porto Seguro, v.38, n.3, p. 207-235, setembro/dezembro, 2017. 
Nietzsche, o perfeccionismo e a democracia: ...

Em "A disputa de Homero", o argumento central é de que os gregos inventaram o agon para redirecionar sua violência e seus instintos destruidores para atividades culturalmente produtivas. Nietzsche associa a origem do agon à da "boa" Eris de Hesíodo (conflito), elevando-se acima deles através da competição. "Por que ninguém deve ser o melhor? Porque com isso a disputa teria de se esgotar e o fundamento eterno da vida da cidade helênica estaria a perigo" (CV/CP, KSA 1. 788). Antes dessa alternativa, os gregos conheciam apenas a Eris "má". Hatab explica:

Excelência é uma forma de diferença que implica graduações e juízos relativos a performances superiores e inferiores, melhores e piores. [...] Ele [Nietzsche] estava interessado em fomentar indivíduos excepcionais e realizações elevadas. [...] é importante, a meu ver, sustentar um sentido de excelência que é vital tanto para as políticas democráticas quanto para a produção cultural. Excelência e democracia são compatíveis, desde que a excelência seja entendida num sentido contextual e performativo, em vez de um sentimento substantivo de superioridade permanente, pervasiva ou essencial (Hatab, 2002, p. 139).

Para Hatab, a contestação e a competição podem ser vistas como fundamentais para o autodesenvolvimento e como um fenômeno intrinsecamente social (Hatab, 2002, p. 134). Como ele argumenta, a ênfase na busca pela autossuperação do indivíduo através do agon apresenta vantagens importantes para a filosofia política contemporânea. Forças da lei não precisam ser vistas como alheias ao self, mas como modulações de uma matriz onipresente de forças dentro das quais os seres humanos localizem esferas relativas de liberdade (Hatab, 2002, p. 139). Logo, a tirania não será evitada pela harmonia e pelo conformismo, mas pela multiplicação do número de centros de poder em um governo e pela afirmação da sua concorrência através da autoafirmação e da desconfiança mútua (Hatab, 2002, p. 140). 
Kamradt, J.

Para Owen, Nietzsche vê a modificação das normas de qualquer prática como uma atividade agonística da liberdade, como uma forma de autossuperação. Já Siemens esclarece que a comunidade agonal de Nietzsche se caracteriza pela ausência de quaisquer regras ou de normas codificadas que poderiam ser usadas para julgar a vitória e a derrota dos indivíduos nas competições. Para Owen, qualquer lei, se estabelecida, além de contenção, dissolve o agon. Logo, esse modelo de perfeccionismo valorizaria a contestação política, capaz de gerar e de ampliar virtudes e capacidades de seus cidadãos. Segundo Hatab, Nietzsche entende que toda e qualquer oposição gera desenvolvimento. Uma das características desse perfeccionismo agonístico é o surgimento dos indivíduos de exceção se dando através da luta e da tensão. Hatab entende que isso coloca o agonismo como um fenômeno que deve ser interpretado como fundamentalmente social. $\mathrm{O}$ perfeccionismo agonista valoriza a

[...] contestação política não por sua capacidade de desafiar a violência e a exclusão, mas por realçar as virtudes e as capacidades dos cidadãos - para a Bildung dos melhores cidadãos. Em outras palavras, do ponto de vista perfeccionista, as políticas agonísticas estão preocupadas principalmente com a boa vida (Fossen, 2008, p. 385).

Como Nietzsche coloca em "A disputa de Homero"

[...] há sempre vários gênios que se estimulam mutuamente para a ação, assim como se mantêm mutuamente nos limites da medida. É esse o germe da noção helênica da disputa: ela detesta o domínio de um só e teme seus perigos, ela cobiça, como proteção contra o gênio - um segundo gênio (CV/CP, KSA 1.789).

Para Siemens, a busca pela perfeição dos indivíduos de exceção só será realizada em comunidades não-coercitivas e que acomodem a liberdade dos indivíduos de exceção para romper com os costumes estabelecidos, criando uma nova lei ou padrão de avaliação. $\mathrm{O}$ agon, 
Nietzsche, o perfeccionismo e a democracia: ...

nessa concepção, é compreendido tanto como uma alternativa quanto como uma forma de resistência para aquele indivíduo de exceção tirânico. Owen expressa que os indivíduos de exceção não possuem um telos. Ao contrário, os indivíduos de exceção manifestam uma luta perpétua para aumentar e expandir os poderes de autogoverno, para que sejam incorporados e passem a apreciar a exposição ao acaso e a necessidade.

Os indivíduos de exceção coordenam uma amplitude de perspectivas conflitantes, de valores, impulsos e esquemas. Os indivíduos de exceção são o resultado final do trabalho acumulado de gerações, uma acumulação de recursos históricos e fisiológicos.

Indivíduos excepcionais ou singulares não figuram como beneficiários exclusivos, mas como os grandes experimentadores, como a chave para perceber uma demanda perfeccionista que tem uma orientação genérica ou geral para a humanidade (Siemens, 2009, p. 30).

Siemens entende que é só através da interação agonística que pode se moldar a qualidade particular transformadora dos indivíduos de exceção. É por isso que ele sugere que o que está em jogo para Nietzsche

[...] não se trata de apenas alguns indivíduos, mas do futuro da humanidade, uma preocupação que tem suas origens num impulso ético positivo que abastece o pensamento de Nietzsche do início ao fim: isto é, sua demanda perfeccionista de que superaremos nós mesmos, que façamos tudo para melhorar ou elevar a espécie, alargando o leque de possibilidades humanas (Siemens, 2008, p. 235).

Owen entende que a realização de um arranjo constitucional legítimo não é uma aproximação a um consenso, mas sua abertura para a contestação democrática, ou seja, para o agonismo. Owen argumenta que, segundo Nietzsche, o "movimento democrático dos nossos tempos" pode evitar seus problemas ao cultivar uma cultura 
Kamradt, J.

agonística, onde seus cidadãos se esforçam para desenvolver suas capacidades em disputas uns com os outros. Enquanto a igualdade liberal busca afirmar todos como iguais uns aos outros, a ética do nobre incentiva os indivíduos de exceção a se afirmarem perpetuamente diante de si e dos outros ${ }^{4}$.

É possível concluir que o perfeccionismo agonístico não pede aos indivíduos para abandonarem seus compromissos éticos e filosóficos quando estiverem em público. Ao invés disso, utiliza a esfera pública para permitir que as pessoas possam se desenvolver e desenvolver concepções do que seria uma vida virtuosa, mesmo que em constante embate com certas regras ou com concepções de bem de outros indivíduos. Para Owen, o perfeccionismo enxergado na filosofia nietzschiana se estabelece com alicerces escorados em ideias já defendidas por Maquiavel, permitindo assim "graus de virtù ética" (Owen, 2002, p. 118). O fato de Nietzsche permitir graus de virtù ética em sua visão trágica de mundo é justificado pelo processo de contínua autossuperação do indivíduo se constituir como a razão para reconhecer o caráter trágico da condição humana, reconhecendo que nossa sujeição "à fortuna (isto é, ao acaso e a necessidade) é uma característica ineliminável da nossa condição e, portanto, que o autogoverno envolve o exercício e o cultivo de capacidades e a disposição necessária para afirmar este fato" (Owen, 2002, p. 118). Para Owen, Nietzsche endossa a posição de que somos sujeitos à fortuna. Logo, a necessidade de se afirmar, de se tornar soberano se constitui como uma vontade manifestada para aumentar nossos poderes frente ao acaso e a necessidade que a vida nos coloca.

Para Owen, então, a política está ligada à ética e a uma cultura pública agonística. Ele argumenta que a política liberal igualitária foca na despolitização do indivíduo. Despolitização que sufocaria o

4 "Dois tipos de igualdade - A ânsia de igualdade pode se expressar tanto pelo desejo de rebaixar os outros até seu próprio nível (diminuindo, segregando, derrubando) como pelo desejo de subir juntamente com os outros (reconhecendo, ajudando, alegrando-se com seu êxito" (MAI/HHI, 300, KSA, p. 14).

230 | Cad. Nietzsche, Guarulhos/Porto Seguro, v.38, n.3, p. 207-235, setembro/dezembro, 2017. 
Nietzsche, o perfeccionismo e a democracia: ...

desenvolvimento das virtudes e a capacidade dos cidadãos. Como ele argumenta, o cultivo da nobreza é prejudicado por uma separação liberal entre o público e o privado e por uma demanda da neutralidade do Estado (Owen, 1995).

A implicação desse argumento é a de que a democracia moderna pode evitar as armadilhas que Nietzsche identifica no "movimento democrático dos nossos tempos" na medida em que cultiva uma cultura política agonal na qual os cidadãos se esforçam para desenvolver as suas capacidades de autogoverno em competição uns com os outros, uma cultura que honra cidadãos democráticos exemplares como modelos que devemos buscar corresponder e superar. [...] Esse é um objetivo central do agon democrático: cultivar cidadãos que apoiem a si mesmos como indivíduos soberanos (Owen, 2002, p. 126).

Para Hatab, o caminho para alcançar esse perfeccionismo agonístico nietzschiano seria mais tangível caso trocássemos o respeito igualitário pelo respeito agonístico. $\mathrm{O}$ respeito igualitário ainda pode colocar indivíduos como antagonistas. Mas segundo Hatab, o respeito democrático proíbe a exclusão e exige a inclusão. $\mathrm{O}$ respeito pelo outro como outro pode evitar um sentimento insípido de "tolerância", um "relativismo" desleixado ou um espírito inapropriado da "neutralidade". Esse respeito decorre não de considerar positivamente os outros, mas de reconhecer e afirmar a contingência e a finitude das próprias crenças e interesses. Assim, o respeito agonístico permite afirmar, simultaneamente, as crenças individuais e coletivas e deixar os adversários se apresentarem como competidores dignos no discurso público. Seria possível falar de respeito sem ignorar o fato de que a política envolve desacordos perpétuos. $\mathrm{O}$ respeito democrático, portanto, seria uma mistura dialógica da afirmação e da negação, uma influência política que implica a concessão a todas as crenças, recusando qualquer crença e a percepção do próprio ponto de vista como agonisticamente implicado com pontos de vista opostos. Em suma, segundo Hatab, será possível combinar: 1) a tendência 
Kamradt, J.

histórica de movimentos democráticos que promoverão a liberdade de expressão, o pluralismo e a liberação das restrições tradicionais; e 2) um perspectivismo nietzschiano e o respeito agonístico para se chegar a um modelo pós-moderno de democracia que proporcione tanto uma abertura não fundacional quanto uma atmosfera de discurso político civil (Hatab, 1995, pp. 69-70).

Como se vê, um perfeccionismo agonístico não é um impedimento para a existência de uma democracia liberal. Serve como um contraponto fundamental para a teoria preponderante que estabelece o nivelamento dos indivíduos. Então, essa busca pela perfeição, esse intenso incentivo ao desenvolver de cada um, que acaba refletindo diretamente no crescimento do outro e da sociedade como um todo, surge como uma opção para a democracia não cair no conformismo tão criticado por autores democráticos, como Mill e Emerson. Como Hatab coloca,

[...] a vida política democrática pode apresentar certos elementos criativos, não igualitários e agonistas em um grau que pode justificar chamá-los de nietzschianos o suficiente para apoiar uma apropriação democrática de Nietzsche (Hatab, 1995, pp. 141-142).

\section{Considerações finais}

O perfeccionismo é um conceito que permanece em disputa no pensamento de Nietzsche. Mas, como procuramos mostrar ao longo do texto, a visão agonística dessa busca pela perfeição pode ser uma ferramenta central no pensamento político do alemão, sendo útil a constante renovação que um ambiente democrático necessita. Logo, o motivo disto é que ela acaba por apresentar uma alternativa viável para uma democracia liberal que quer ser igualitária, mas não de uma igualdade conformista com o indivíduo e com a sua posição de mediocridade. Ao contrário, busca auxiliar uma democracia liberal igualitária que coloque os indivíduos em posição de almejar novas

232 | Cad. Nietzsche, Guarulhos/Porto Seguro, v.38, n.3, p. 207-235, setembro/dezembro, 2017. 
Nietzsche, o perfeccionismo e a democracia: ...

posições, objetivos e que torne a existência um constante buscar. Mesmo assim, se um perfeccionismo agonístico oferece possibilidades interessantes para um revigoramento do liberalismo democrático, também traz perigos que não apresentam nenhum tipo de resolução fácil. O maior destes é descobrir a melhor forma de enfrentar aquele tipo de indivíduo que deseja ser o único soberano, não aceitando o perpétuo combate do agon e desejando encerrá-lo, colocando-se como único indivíduo superior. É o embate contra este tipo de indivíduo que se deve empreender daqui para frente.

Nietzsche, perfectionism and democracy: tensions between Rawls, Cavell and the agonists

Abstract: At the center of his political thinking, Nietzsche encourages the quest for the perfection of individuals. It is the dispute for the meaning of perfectionism of Nietzsche's thought by different currents the purpose of this article. Rawls reads a Nietzschean perfectionism that is elitist, anti-egalitarian, and bound up with aristocratic regimes. This was a prevalent reading of the thinker. But in the last 25 years, other interpretations have emerged for the quest for Nietzschean perfection. One defends a moral perfectionism in the author's thought, which would be egalitarian and compatible with the democratic environment. Another, more recent, argues for an agonistic perfectionism, aiming at the perpetual struggle to overcome itself as fundamental to the democratic environment.

Keywords: Perfectionism - Nietzsche - Equality - Democracy -Aristocratism.

\section{Referências bibliográficas}

CAVELL, Stanley. Conditions Handsome and Unhandsome: The Constitution of Emersonian Perfectionism. Chicago: University of Chicago, 1990.

.Conditions nobles et ignobles: La Constitution du perfectionnisme moral émersonien. Paris: L’Eclat, 1993. 
Kamradt, J.

CONANT, James. "Nietzsche's Perfectionism: A Reading of Schopenhauer as Educator". In: SCHACHT, R. Nietzsche's Postmoralism: Essays on Nietzsche's Prelude to Philosophy's Future. Illinois: Cambridge University Press, 2001.

CONWAY, Daniel. Nietzsche \& the political. London: Routledge, 1997.

FOSSEN, Thomas. "Agonistic Critiques of Liberalism: Perfection and Emancipation". Contemporary Political Theory, v. 7, pp. 376-394, 2008.

HATAB, Lawrence J. A Nietzschean Defense of Democracy: An Experiment in Postmodern Politics. Chicago, Illinois: Open Court Publishing Co, 1995.

. "Prospects for a Democratic Agon: Why We Can Still Be Nietzscheans". The Journal of Nietzsche Studies, v. 24, pp. 132-146, 2002.

LEMM, Vanessa. "Is Nietzsche a perfectionist? Rawls, Cavell and the politics of culture in Nietzsche`s "Schopenhauer as educator"'. The Journal of Nietzsche Studies, Issue 34, pp. 5-27, 2007.

"Nietzsche y liberdad individual: Rawls, Cavell y el debate sobre el valor del perfeccionismo para la democracia". Alpha: Revista de Artes, Letras y Filosofia, $\mathrm{n}^{\circ}$ 28, pp. 87-104, 2009.

NIETZSCHE, Friedrich. Sämtliche Werke. Kritische Studienausgabe. Berlin/ München: de Gruyter/dtv, 1988.

. Além do bem e do mal. Trad. Paulo César de Souza. São Paulo: Companhia das Letras, 2015.

. "A Disputa de Homero". In: Cinco Prefácios para Cinco Livros Não Escritos. Tradução e prefácio de Pedro Süssekind. 2. ed. Rio de Janeiro: Ed, 7 letras, 2005.

. "O Estado Grego". In: Cinco Prefácios para Cinco Livros Não Escritos. Tradução e prefácio de Pedro Süssekind. 2. ed. Rio de Janeiro: Ed, 7 letras, 2005.

. Humano, demasiado humano. Trad. Paulo César de Souza. São Paulo: Companhia das Letras, 2005.

. Schopenhauer como Educador. Tradução Adriana M. Saura Vaz. Campinas: Faculdade de Educação/UNICAMP, 1999.

234 | Cad. Nietzsche, Guarulhos/Porto Seguro, v.38, n.3, p. 207-235, setembro/dezembro, 2017. 
Nietzsche, o perfeccionismo e a democracia: ...

OWEN, David. "Equality, democracy, and self-respect: reflections on Nietzsche's agonal perfectionism". The Journal of Nietzsche Studies, Issue 24, p. 113-131, 2002.

. Nietzsche, Politics and Modernity, London: Sage, 1995.

. "Nietzsche's Freedom: The Art of Agonic Perfectionism". In: Nietzsche and Political Thought. Edited by Keith Ansell-Pearson. London: Bloomsbury, pp. 71-81, 2013.

RAWLS, John. Uma teoria da justiça. São Paulo: Martins Fontes, 2002

SIEMENS, Herman. "Agonal Communities of Taste: Law And Community In Nietzsche's Philosophy Of Transvaluation". The Journal of Nietzsche Studies, v. 24, 2002, pp. 83-112.

“Nietzsche's Critique of Democracy (1870-1886)". Journal of Nietzsche Studies, v. 38, 2009, p. 20-37.

. "Yes, No, Maybe So... Nietzsche's equivocations on the relation between democracy and "grosse Politik"'. In: Nietzsche, Power and Politics. Edited by Siemens, Herman / Roodt, Vasti. Walter de Gruyter, pp. 231-268, 2008.

VACCARI, Alessio. "The perfectionist dimension in Friedrich Nietzsche's critique

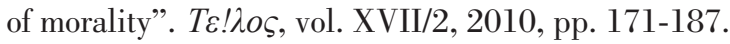

Artigo recebido para publicação em 29/03/2017

Artigo aceito para publicação em 15/05/2017 